\title{
Acoustic Repertoire of the Philippine Tarsier (Tarsius syrichta fraterculus) and Individual Variation of Long-Distance Calls
}

\author{
Milada Řeháková-Petrů, ${ }^{1,2,3}$ Richard Policht, ${ }^{4,5}$ and Lubomír Peške ${ }^{6}$ \\ ${ }^{1}$ Decin Zoo, Pastýřská Stěna, Žižkova 15, 40502 Děčín, Czech Republic \\ ${ }^{2}$ Department of Zoology, Faculty of Science, Charles University in Prague, Viničná 7, 12844 Praha, Czech Republic \\ ${ }^{3}$ Tarsius, o. s., NGO, Na Pěšině 267, 40505 Děčín, Czech Republic \\ ${ }^{4}$ Institute of Animal Science, Department of Ethology, Přátelství 815, 10400 Praha Uhřinèves, Czech Republic \\ ${ }^{5}$ Department of Forest Protection and Game Management, Faculty of Forestry and Wood Sciences, \\ Czech University of Life Sciences Prague, Kamýcká 129, 16521 Praha 6, Czech Republic \\ ${ }^{6}$ Slezská 43, 13000 Praha 3, Czech Republic
}

Correspondence should be addressed to Milada Řeháková-Petrů, miladare@seznam.cz

Received 9 March 2012; Revised 28 April 2012; Accepted 29 April 2012

Academic Editor: Randy J. Nelson

Copyright ( 2012 Milada Řeháková-Petrů et al. This is an open access article distributed under the Creative Commons Attribution License, which permits unrestricted use, distribution, and reproduction in any medium, provided the original work is properly cited.

We present the spectrographic description of the vocal repertoire of the Philippine tarsier (Tarsius syrichta fraterculus), a solitary living nocturnal primate for which a very limited information about acoustic communication exists to date. The majority of vocalizations were performed around sunset and, less frequently, at sunrise. We identified eight call types. Five calls recorded during communication between adults included three long-distance calls-loud call, smack-whistle, and whistle-then a soft locust-like chirp and a bird-like trill. Two other calls—cheep and twitter-were recorded during mother-infant communication. One distress call was emitted by adults during handling. All calls were performed in the $9752 \mathrm{~Hz}$ to more than $22 \mathrm{kHz}$ frequency range. This study provides the first evidence of individual variation in the long-distance calls performed by tarsiers. Moreover, our study provides a basis for future comparison within as well as between tarsier species taxonomy. Bioacoustic methods can be used in monitoring of these cryptic species and determining their distribution range. Thus, bioacoustic studies can help to improve conservation strategies of different population/species.

\section{Introduction}

Many nonhuman primates use vocalizations as a primary mode of communication. Following studies of monkey and apes, investigators have begun to understand the role of the auditory communication in nocturnal, mainly strepsirhine, primates during the past decades, for example, [1-9]. Similarly to anthropoid primates, strepsirhines use vocalizations to contact conspecifics, announce territorial boundaries, or announce a potential threat. Vocalization is also used in spacing and group coordination $[7,10-12]$. The most conspicuous signals that are most commonly researched during studies of primate communication are the long-distance calls, often referred as loud calls. Long-distance calls have received much attention from researchers studying nocturnal primate communication; however, complete acoustic repertoires including the close-range communication between conspecifics of nocturnal primates have only been described for a limited number of species (e.g., bush babies [1, 7], greater bamboo lemur [13], and crowned lemur [2]).

Tarsiers are small nocturnal primates native to Asia. The Philippine tarsier (Tarsius syrichta) is the only species living in the Philippines. Due to the nocturnal and cryptic nature of tarsiers, vocalizations and scent marking have been recognized as main modes of communication [14, 15]. A recent morphological study of the brain structure of spectral tarsier (T. spectrum) has also revealed a developed auditory system tarsiers [16]. As in other nocturnal primate species, 
the most conspicuous acoustic signals in tarsiers are loud calls which are emitted regularly at dusk and dawn $[14,15$, 17-20]. In T. spectrum, 15 different calls were characterized, eight calls reportedly performed by adults, and seven by juveniles [21]. There is little information concerning the acoustic behaviour of T. bancanus. Niemitz [18, 22] reported that $T$. bancanus cannot often be heard in the wild; in concurrence, Yustian [23] did not record any vocalization during his study. These findings are in opposition with those of Compton and Andau [24], who reported vocal concerts of up to five animals calling at one time. Niemitz [22] distinguished four basic patterns of vocalization performed by adult tarsiers and an additional three calls by infants. The only reports concerning the repertoire of the Philippine tarsier were given by Wharton ([25] cited in [22]) who described three types of vocalization; a loud piercing call of a single note, a chirping locust-like communication, and a soft bird-like trill and by Wright and Simons [26] who described three types of calls recorded in male captive tarsiers.

Researchers of acoustic communication have recognized that individually distinct acoustic features occur in a large number of birds and mammals. Individual differences in loud calls have been reported in a range of primate species (e.g., Lemur catta [5], Eulemur rubriventer [27], Cebuella pygmaeus [28], Callithrix kuhli [29], Ateles geoffroyi [30], and Presbytis thomasi $[31,32])$. Call-individuality permits individual recognition and enables the recognition of neighbours or strangers reviewed in [33]. In a cryptic, solitary living, and nocturnal animal as the Philippine tarsier, we expect that long-distance communication holds great importance in informing listeners about the presence and identity of another individual. So far, individual variability of acoustic signal has not been tested in tarsier species.

In our paper, we present the first systematic attempt to determine the vocal repertoire of adult males, females, and infants of the Philippine tarsier and present spectrographic descriptions and analyses of all calls recorded during the study period. Furthermore, for the first time in tarsiers, we provide analyses of long-distance calls to reveal possible individual variability.

\section{Methods}

2.1. Study Site and Subjects. This study was conducted on Bohol Island, Philippines. From March to July 2009 radiotelemetry was carried out at the Philippine Tarsier Sanctuary in Corella, Bohol $\left(9^{\circ} 41^{\prime} \mathrm{N}, 123^{\circ} 57^{\prime} \mathrm{E}\right.$ ), (elevation 100 $200 \mathrm{~m}$ ) and from February 2010 to December 2010 in Forest Academic Research Area, Bilar, Bohol $\left(9^{\circ} 44^{\prime} \mathrm{N}, 124^{\circ} 06^{\prime} \mathrm{E}\right)$ (elevation $220-380 \mathrm{~m}$ ). We recorded vocalization of a total of 10 adult animals ( 3 males, 7 females), radiocollared, and tracked during our study, including one adult female rescued from poachers together with her infant. In addition, we recorded communication of three mother-infant pairs. The first infant was born to the radiocollared mother. In this case, observation was limited to one month. After this period, the infant was lost because of predation [34]. The second infant, born in a semicaptive enclosure in Corella [35], was observed irregularly for two months until the end of the first study period. The third infant (age around 1-2 weeks), was observed and recorded together with its mother only for one day during a rescue and release to the wild. We also recorded vocalization of other animals found in the locality ad libitum. We did not identify these animals individually and were not able to determine their sex. We considered animals as distinct individuals, when either recorded at one place at one time (two unknown animals clearly recognizable from each other, unknown animal in proximity of identified radio-collared animal), or at different places which were separated enough not to be within a home-range of a single individual. In the latter case, our decision was based on the home-range sizes previously reported $[15,36]$ as well as those inferred in this study from the radio-collared animals. We also considered the local terrain, as valleys, rivers, brooks, meadows, and so forth, represent natural barriers between home-ranges. In total, we recorded the vocalizations of 25 individuals including three infants.

2.2. Recording. The data were collected during 154 observational nights (58 in Corella and 96 in Bilar) between 17:30 and 06:00 hours. The recordings were obtained during radio-telemetric observation during either whole night period or periods covering only part of the night. In the latter case, the periods were planned to provide comparable coverage for each part of the night. Vocalization was recorded whenever heard. Additionally, during daytime we recorded animals being handled for radio-collaring and while rescuing tarsier mother and infants from poachers. Vocalizations were recorded using digital recorders Olympus LS-10 and LS-11 with built-in microphone. For a limited number of recordings from further distance Sennheiser ME 66 directional microphone with K6 powering module were used. We used digital format 16 bit PCM.

2.3. Data Analyses. Calls were analyzed using the bioacoustic software Avisoft (Avisoft-SASLab Pro Software, Version 5.1.01). Only good quality recordings with low background noise and call intensity sufficient for determination of all necessary parameters were analysed. The recordings were obtained using $44.1 \mathrm{kHz}$ sampling frequency at the beginning of the study and $96 \mathrm{kHz}$ sampling frequency after we realized that some of the calls reach above $22 \mathrm{kHz}$. When sufficient number of calls in each call type was recorded with the higher sampling rate (only in chirp and twittersee Section 3.1), we analysed the spectrograms in full range. In other call types, the $96 \mathrm{kHz}$ recordings were resampled to $44.1 \mathrm{kHz}$ in order to unify the spectrogram parameters for further analyses. If the maximum $F$ reached above $22 \mathrm{kHz}$, it was set as $22 \mathrm{kHz}$. Spectrograms were created using following parameters: FFT 1024, Hann window, frame size $100 \%$, overlap $87.5 \%$, frequency resolution $43 \mathrm{~Hz}$, and time resolution $2.9 \mathrm{~ms}$. Numbers of calls are summarized in Table 1. For each call the following acoustic parameters were measured; start frequency (start $F$ ), minimum frequency $(\min F)$, maximum frequency $(\max F)$, and duration. In case of chirp, trill, and twitter (see Section 3.1), the 
TABLE 1: Acoustic parameters of eight call types identified in the repertoire of the Philippine tarsier-start frequency (start $F)$ (mean $( \pm$ SD)) $(\mathrm{Hz})$, minimum frequency $(\min F)(\mathrm{Hz})$, maximum frequency $(\max F)(\mathrm{Hz})$, duration $(\mathrm{s})$, and number of notes contained in the callmean (min-max) ( ${ }^{*} \max F$ reached above $22 \mathrm{kHz}$ several times). It was difficult to measure min $F$ and max $F$ in distress call; therefore, only start $F$ (start of the fundamental frequency) and duration was measured. Numbers of analyzed calls (individuals) are given in each call type.

\begin{tabular}{|c|c|c|c|c|c|c|}
\hline & $\operatorname{start} F(\mathrm{~Hz})$ & $\min F(\mathrm{~Hz})$ & $\max F(\mathrm{~Hz})$ & Duration (s) & Notes & $\begin{array}{c}n \text { calls } \\
\text { (individuals) }\end{array}$ \\
\hline Loud call & $14310( \pm 1555)$ & $4855( \pm 809)$ & $19340 *( \pm 1961)$ & $0.28( \pm 0.29)$ & 1 & $358(14)$ \\
\hline Smack-whistle & $17730( \pm 2854)$ & $8178( \pm 2231)$ & $17731^{*}( \pm 2855)$ & $0.46( \pm 0.06)$ & 1 & $133(8)$ \\
\hline Whistle & $18360( \pm 2792)$ & $13507( \pm 1263)$ & $18366^{*}( \pm 2799)$ & $0.38( \pm 0.06)$ & 1 & $119(10)$ \\
\hline Chirp & $20537( \pm 2370)$ & $12093( \pm 2316)$ & $22445( \pm 1718)$ & $0.66( \pm 0.19)$ & $15(6-25)$ & $39(7)$ \\
\hline Trill & $9752( \pm 4351)$ & $3664( \pm 1495)$ & $21451( \pm 1427)$ & $5.20( \pm 2.15)$ & $4(2-7)$ & $14(4)$ \\
\hline Cheep & $15702( \pm 2015)$ & $15702( \pm 2015)$ & $16273( \pm 2494)$ & $0.23( \pm 0.10)$ & 1 & $71(3)$ \\
\hline Twitter & $11343( \pm 2741)$ & $11343( \pm 2741)$ & $21881( \pm 2533)$ & $0.77( \pm 0.20)$ & $4(1-5)$ & $20(1-2)$ \\
\hline Distress & $1309( \pm 678)$ & & & $0.15( \pm 0.14)$ & 1 & $87(5)$ \\
\hline
\end{tabular}

number of notes (single uninterrupted units of a call) contained in the call was recorded. Long-distance calls (loud call, long whistles, and whistles) were analysed in further detail and additional frequency and temporal parameter measurements were taken (Figure 4). In loud call type II (see Section 3.1), we measured additional acoustic parameters using LMA 2008 (developed by K. Hammerschmidt). LMA is software specifically designed to extract different sets of call parameters from acoustic signals. This software calculates a statistical distribution of the frequency amplitudes in the spectrum including dominant frequency bands and their local and global modulations, global energy distribution, and parameters describing main energy peaks in more detail $[37,38]$. The acoustic measurements were done onscreen using cursor. Only in case of LMA the parameters were measured by the software.

2.4. Statistical Analysis. Histogram of the distribution of acoustic activity during night was calculated from the data set collected between February and April 2010, which was the period when the data collection was the most intense. We calculated number of calls in each 15 minutes interval between 17:45-06:00. If the calls occurred in a sequence, each call type was calculated only once. During the 73 observational nights in this period, 130 calls were recorded.

To provide a detailed description of the acoustic repertoire, we considered all vocalizations recorded during the whole study period. All call types recorded during our study were confirmed as tarsier calls when the animal was visible. If the tarsier was not visible or in case of noncollared tarsier where we could not always visually confirm presence of the animal, the sounds were identified based on their similarity to sounds recorded from visually confirmed animals. The call types of the vocal repertoire were categorized by ear and visual inspection of spectrograms. To test for individual differences within each of the three long-distance calls, we used forward stepwise discriminant function analysis (DFA) in order to reduce number of variables using parameters described in Figure 4. To validate results of the DFA, we used leave-one-out method of cross-validation (SPSS 13.0). Highly correlated variables $(r>0.80)$ were excluded from the analyses and the remaining variables were $\mathrm{LN}$ - or $\mathrm{LN}(x+1)$ transformed. Statistical results were considered significant when $P<0.05$. We compared individuals for which at least five calls were recorded. Animals with lower number of recorded calls were excluded from the analysis.

\section{Results}

The acoustic communication was heard at any time of the night (and during day in case of stress situations as handling or rescue from poachers); however, most of the vocalizations occurred around sunset and to a lesser degree before sunrise. The peak activity during February and April 2010 was at 18:00-18:45 and 05:00-05:45, corresponding with sunset which varied between 18:10-18:16 and sunrise between 05:05-05:44 during that period (Figure 1). The adult Philippine tarsier vocalized alone in most of the cases. On five occasions, simultaneous vocalization of two adult individuals was recorded, in one case tarsiers on different hills vocalized, on four occasions tarsiers in closer distance (around $10 \mathrm{~m}$ ) vocalized simultaneously. Only once four to five animals called at the same time. Philippine tarsiers are relatively quiet animals. Except the three studied motherinfant pairs that communicated very frequently in periods when they were together and used different call types, vocalization was not heard very frequently during the night.

3.1. Acoustic Repertoire. We recorded eight main types of acoustic signals performed by the Philippine tarsier; five during communication between adults, two calls during motherinfant communications, and one distress call emitted by adults during handling.

3.1.1. Spectrographic Description and Context of Use. All of the calls described were easily distinguishable by ear and by visual inspection of their spectrograms. Measured parameters (start $F$, min $F$, max $F$, and duration) of each call type and number of calls and individuals are given in Table 1 . In many recordings, the context in which the calls were produced could not be determined, as tarsiers are very 


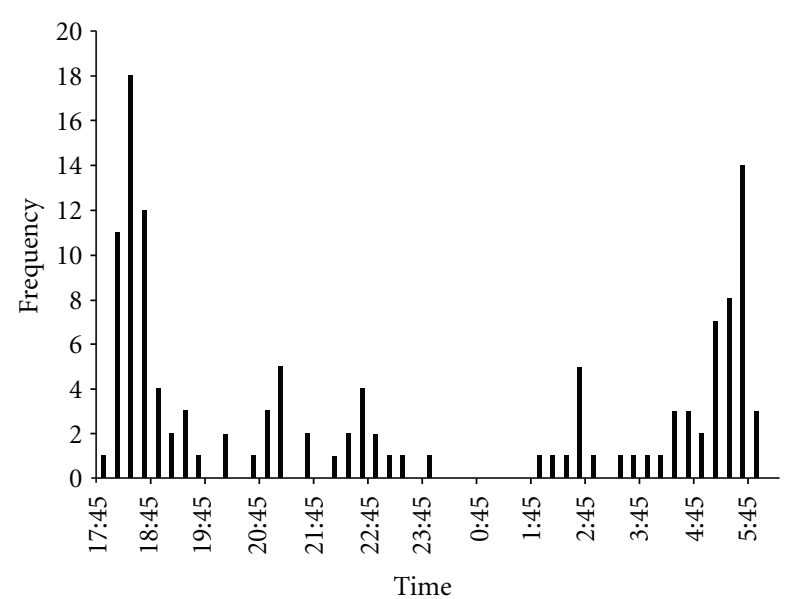

FIGURE 1: Histogram of distribution of acoustic activity as recorded during February and April 2010 in Bilar locality. Peak activity is shown between 18:00-18:45 and 5:00-5:45.

difficult to observe. The exceptions are described for each call type below.

Loud Call. The loud call (Figure 2(a)) is a single-note vocalization, carrying relatively far through the habitat. They could be reliably heard and identified from distance at least $50 \mathrm{~m}$ during our study (however, we did not focus on measuring of the maximal distance). The loud call was recorded mainly around sunset in proximity to the sleeping site but also during the night. Loud call was used also in mother-infant communication, apparently by one to get attention of the other, or when the mother was returning to the parked infant after a while. On two occasions, loud call was reported in situation when the tarsier got scared during unexpected encounter during the day. The loud-call note consists of two distinct parts; the whistle part with a limited frequency range and the final smack part with a substantial frequency range (Figure 2(a)). The loud calls showed a certain level of variation. Based on the visual inspection of the spectrograms, we divided the loud calls into three subcategories (Figure 3). This further categorization was supported by the histogram of the length of the whistle part which showed three peaks: type I (length of the whistle part is between 0.003 and $0.045 \mathrm{~s})$, type II $(0.046-0.130 \mathrm{~s})$, and type III $(0.131-0.316 \mathrm{~s})$. When the loud call was given repeatedly, the interval between start of one call and start of another call in the sequence was $7.55 \mathrm{~s} \pm 6.11$ (mean $\pm \mathrm{SD}$ ) $(n=452)$.

Smack-Whistle. Similarly as the loud call, the smack-whistle (Figure 2(b)) is a relatively loud single-note call. Also the smack-whistle call consists of two parts; the whistle which is more frequency modulated than that of the loud call, and the final smack part (Figure 2(b)), less prominent than in case of loud calls.

Whistle. Similarly as the two calls mentioned above, the whistle (Figure 2(c)) is a relatively loud, single-note call. In contrast to the smack-whistle, this call type consists only of the whistle part and lacks the smack vocalization.

Chirp. The chirp (Figure 2(d)) is a soft call. It was heard mainly in proximity to the sleeping site in the evening or in the morning. During the communication that we observed between the mother and her infant it was the most frequent call used by both, for example, when a mother was directing the infant to follow her. Chirps were also emitted by a mother when she lost her infant after a month [34], and called it during the following nights. Chirp consists of several short, rapid, broad-band notes in a descending series.

Trill. The trill (Figure 2(e)) was the rarest signal performed during the study. In one case, the adult male was observed climbing towards the top of the tree (around $4 \mathrm{~m}$ ), and then he started to trill. Another tarsier was heard trilling in proximity of other two individuals. In the 14 other cases (4 individuals) analyzed during our study, the context was not observed. This signal is much quieter than the loud call. This harmonic call consists of several units (notes), contains strongly frequency-modulated elements (Table 1), and its complexity is unique in the whole repertoire. It was not given repeatedly. However, it is several seconds long, and its duration also distinguishes it from the other call types.

Cheep. The cheep (Figure 2(f)) is a single-note call, usually emitted repeatedly in a sequence. It was recorded from both mother and her infant whilst being rescued from poachers. The animals were rescued during the day and kept in the small cage the whole afternoon before releasing to the wild in the evening. It was recorded also in a free ranging mother, where it was involved in the sequence where loud calls, whistle, and also chirp occurred.

Twitter. This signal (Figure 2(g)) was recorded during communication between a mother and infant during rescue from poachers. It was observed to be performed by the infant in 13 cases, but in some cases ( 7 calls) it was not determined if the infant or the mother was emitting the sound. The signal has two parts; the first longer cheeping sound is followed by several short, frequency-modulated twittering notes (1-5, mean 4$)$.

Distress Call. This call (Figure 2(h)) was recorded only during handling when we were attaching the collars. This call contained fundamental frequency with $2-12$ (5 on average) harmonic frequency bands.

3.1.2. Call Types in a Sequence. The described signals occurred as single calls or as a part of a longer sequence. Animals often used loud calls, smack-whistles, and whistles together in one sequence. Cheeps occurred as a single call or repeated twice or three times. It was also followed by loud calls. In one female (mother), we recorded a sequence containing loud calls, whistles, chirps, cheep, and even a trill. 


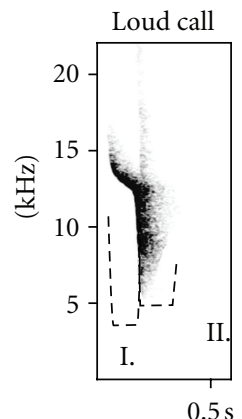

(a)

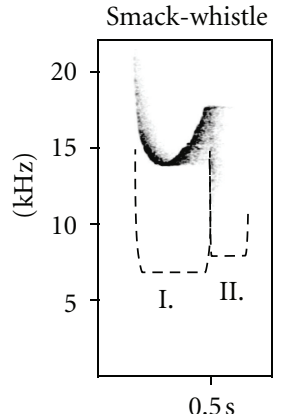

(b)

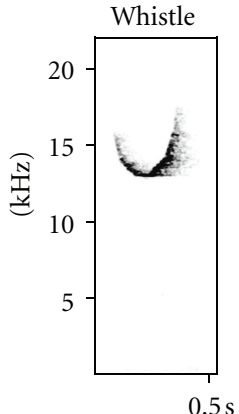

(c)

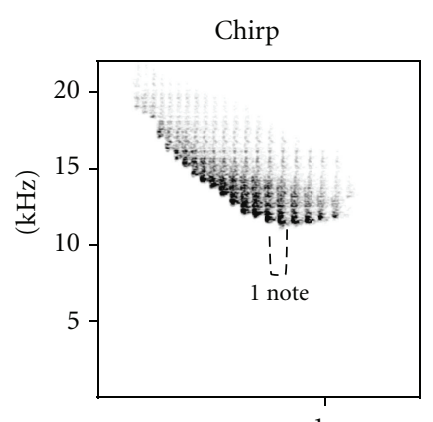

(d)

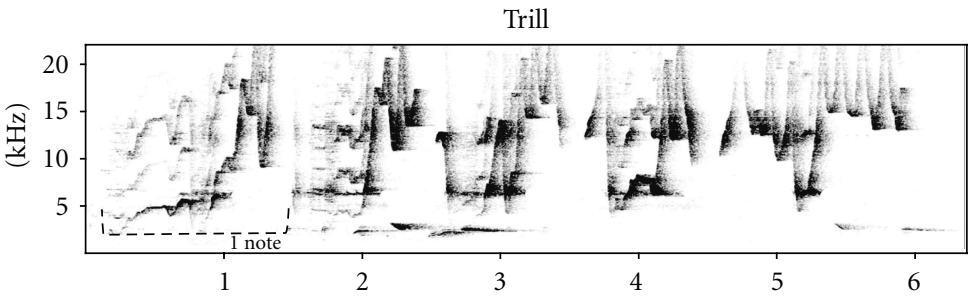

(s)

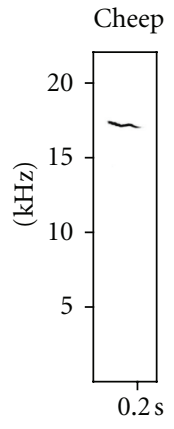

(f)

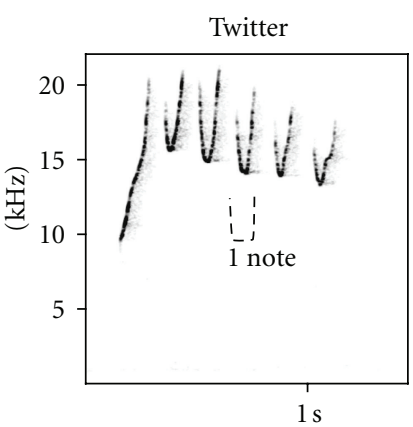

(g) (e)

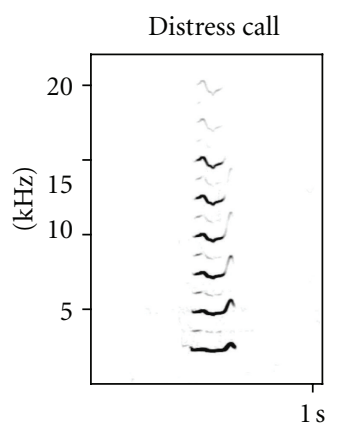

(h)

Figure 2: Spectrograms of eight call types reported in the Philippine tarsier (a-h). In loud call (a) and smack-whistle (b), the two parts are labeled I. whistle part, II. smack part, in chirp (d), trill (e), and twitter (g) the note is labelled, other calls are single-note calls.

\subsection{Individual Variation}

Whistle. 91 whistles performed by four individuals were categorized with $93 \%$ success to the correct individual caller. The resulting DFA model (Wilks lambda $=0.018$ ) included five acoustical parameters; start $F$, 2nd part FM, 1st part duration, 2nd part duration, whistle duration (Figure 4). The first two significant canonical functions with eigenvalues $>2$ described $89 \%$ of variation. The most important parameters were start $F$ which was correlated with the first canonical function $(r=0.83)$ and 1st part duration $(r=0.64)$ and 2 nd part duration $(r=-0.41)$ which was correlated with the second canonical function.

Smack-Whistle. 105 smack-whistles from seven individuals were categorized to the correct individual caller with a $72 \%$ result based on a model (Wilks lambda $=0.022$ ) containing four acoustic variables (start $F$, 2nd part FM, 1st part duration, and whistle duration (Figure 4). Two canonical functions with eigenvalues $>1$ described $90 \%$ of variation. The most important acoustic parameters for individual distinction were start $F$ which was correlated with the first canonical function $(r=0.99)$ and 2nd part FM which was correlated with the second canonical function $(r=0.78)$.

Loud Call. 271 loud calls emitted by 12 individuals were classified with $59 \%$ correct classification. The discrimination model (Wilks lambda $=0.017$ ) included 9 acoustic parameters (start $F$, bend $F$, min $F$, whistle FM, smack FM, whistle duration, smack duration, centre FM, and centre duration) (Figure 4). Two canonical functions with eigenvalues $>1$ described $57 \%$ of variation. Consequently, we tested the 


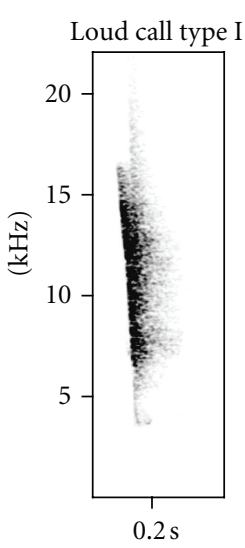

(a)

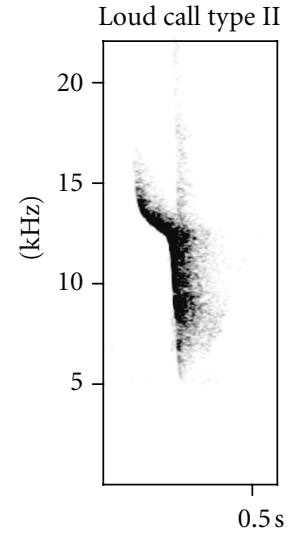

(b)

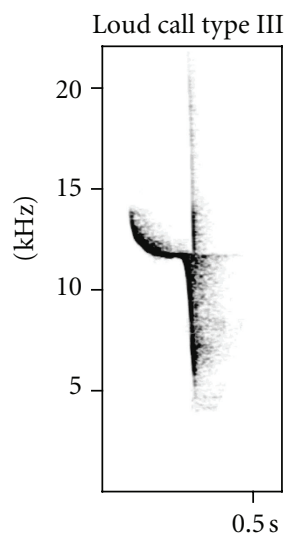

(c)

FIgURE 3: Three types of loud calls classified on the basis of the length of the whistle part $(\mathrm{a}-\mathrm{c})$.

three subtypes of loud call separately, which increased the reliability of correct individual classification. 73 cases of loud call type I performed by six individuals were categorized with $71 \%$ success to the correct individual, 150 cases of loud call type II of eight individuals were categorized with $67 \%$ success and 53 cases of loud call type III produced by four individuals were categorized with $94 \%$ discrimination rate to the correct individual.

In loud call type II, the most common call type recorded in the Philippine tarsier, additional parameters that describe the statistical distribution of the frequency amplitudes in the spectrum were measured (see Section 2). The resulting DFA model (Wilks lambda $=0.001$ ) included 9 acoustical variables. The most important parameter was maximum relative amplitude of global frequency peak $(r=-0.43)$. The first four canonical functions with eigenvalues $>2$ described $93 \%$ of variation and 146 calls performed by eight individuals DFA were correctly classified at $85 \%$.

\section{Discussion}

In our paper we provide the first spectrographic description of the acoustic repertoire of the Philippine tarsier. Eight call

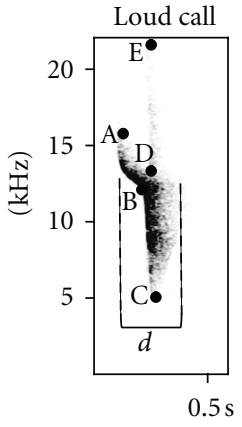

(a)

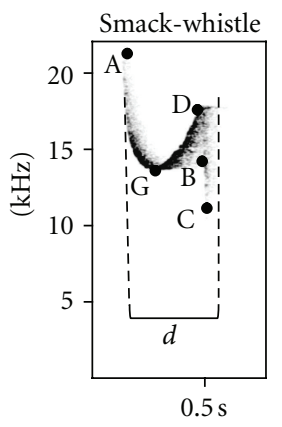

(b)

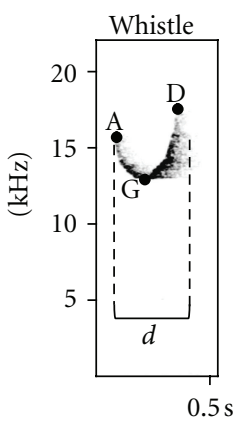

(c)
FIGURE 4: Parameters measured for analyses of loud calls, smackwhistles, and whistles. In points (A-E) indicated in the spectrograms, frequency and time parameters were measured and used for calculating additional parameters. For analyses of loud calls, we used start $F$ (A frequency), bend $F$ (B frequency), min $F$ (C frequency), middle $F$ ( $\mathrm{D}$ frequency), whistle FM (A-B frequency modulation), smack FM (B-C frequency modulation), centre FM (B-D frequency modulation), whistle duration (A-D duration), smack duration (B-C duration), centre duration (B-D duration), and duration (d). For analyses of smack-whistles and whistles, the following parameters were used: start $F$ (A frequency), second peak $F$ (D frequency), bottom $F$ ( $G$ frequency), 1st part FM (A-G frequency modulation), 2nd part FM (G-D frequency modulation), whole FM (A-C frequency modulation) (only in smack-whistles), 1st part duration (A-G duration), 2nd part duration (G-D duration), whistle duration (A-D duration), and duration (d).

types were identified in the free-ranging Philippine tarsiers (Tarsius syrichta fraterculus) on Bohol Island; five calls in communication among adult Philippine tarsier, two other calls in communication of mother and its infant, and one distress call emitted by adults during handling. The three call types reported previously by Wharton ([25] cited in [22]) were confirmed during our study and labelled as loud call, chirp, and trill. Loud call II in study of Wright and Simons [26] probably corresponds with loud call or smack-whistle, as labelled in our study, other calls could not be confirmed due to lack of description.

The loud call, smack-whistle, and whistle were the most prominent calls identified in the acoustic repertoire of the Philippine tarsier. The loud call was the most common call type performed. All the three calls often occurred in one sequence. The detailed investigations revealed that three types of loud calls can be determined. Considering a very small body size (100-150 g), habitat type, and quite strong background noise (insects, frogs, etc.), these three calls are quite loud and relatively far carrying. Therefore, we suppose that they are used for long-distance communication and may serve territorial or mate attraction function. However, loud call was also reported when the animal was suddenly scared or in mother-infant communication. The exact function of the loud calls, as well as the other two long-distance calls, requires further investigation. During our study, tarsiers called mainly around sunset, in proximity of their sleeping sites. Loud calls concentrated in a short time period (dusk and down) have been reported in all studied tarsier species 
$[14,15,17,19,20]$. The Sulawesi tarsiers, T. spectrum, T. dianae, and T. lariang, perform duet calls $[14,17,19-21]$ that have both territorial and also social functions. Studies of communication in T. spectrum indicate that vocal duetting in this species is a multifunctional display, serving a role in territoriality, mate attraction, and also as vocal mate guarding [21]. Neither Tarsius syrichta nor Tarsius bancanus perform vocal duets, which can be related to their suggested social system and solitary lifestyle. However, calling during a short interval, "a time window," may be sufficient to inform neighbours of the continued presence of the territory holders [39]. This may explain why calls occurred mainly around the sunset in the solitary Philippine tarsier.

Another signal recorded during our study, the chirp, is a soft, twittering call usually heard in the proximity of sleeping sites. It was also frequently performed during communication between mothers and their infants. The trill, a bird-like sound, was the rarest signal recorded in the wild adult tarsier. Based on one observation of an adult male climbing high on the tree before trilling, and another tarsier trilling in proximity of other two individuals during mating season (December) [15], we suggest that the function of the trill may be territorial or in mate attraction. The last call type recorded in adults, the distress call, was a human-induced call recorded during handling of adults.

Mother-infant communication was an important part of our study. This is the first time that vocalization of infants has been recorded and described in the Philippine tarsier. Tarsiers give birth to one offspring once in a year [40]. Infants are not continuously transported by their mother or other group members following birth, rather, they adopt a cacheand-carry infant-caretaking strategy. Infants are transported in the mother's mouth and then parked on branches while the mother forages nearby [14, 40, pers. observ.]. Communication is, therefore, limited to occasions when the mother is with her infant. During these periods, calls are emitted very frequently by both the mother and infant. Most often they perform chirps, less often loud calls, suggesting that these signals may be used in a variety of contexts. Two signals, cheep and twitter, were recorded uniquely during mother infant communication. Cheep was recorded in rescued animals kept in small cage before releasing, therefore, this sound is considered as a kind of distress call. However, it was recorded also in a free-ranging mother, where it was involved in the sequence where loud calls, whistle, and also chirp occurred. We had the opportunity to study mother-infant communication in different contexts including distressing situations after poaching and releasing to the new environment and after the mother lost her infant [34]. Unfortunately, the period of our study concerning mother-infant communication was limited. It is possible that with further research, conducted in various contexts, the number of described signals may increase.

The described signals occurred individually or in a sequence of a single signal or together with other signals. In one female (mother), we recorded a sequence containing loud calls, whistles, chirps, cheep, and a trill. Therefore, it is difficult to determine the exact meaning and contextual of use of each signal without further detailed observation, which is extremely difficult in the wild Philippine tarsier. Six out of the eight recorded signals reached above $22 \mathrm{kHz}$ in several cases. The highest frequency was recorded in one case of a trill, reaching above $44 \mathrm{kHz}$. Recently, Ramsier and colleagues [41] have proved that Philippine tarsier can communicate in pure ultrasound, and this topic surely deserves further investigation.

It has been suggested that the richness of the acoustic repertoire may reflect the complexity of the social system of the species [42-45]. Although we do not have enough data for a detailed analysis, it is worth to notice that the number of calls reported during our study resembles the richness of acoustic repertoire of another solitary living tarsier species, $T$. bancanus $[18,22,23,46]$, rather than quite social T. spectrum, where twice as many calls were described [14, 21, 47-49].

For the first time in tarsiers, we tested if long-distance calls differ acoustically between individuals. Three call types - the loud call, smack-whistle, and whistle-are used for long-distance communication (considering their loud and long carrying character). Therefore, we expected the highest potential for individual variability in these calls. Our results showed that the individual variability occurs in all three long-distance calls of the Philippine tarsier. In the case of whistle $93 \%$ of calls were classified correctly to an individual, followed by $72 \%$ of correct classification of smack-whistle. Start frequency was the most important parameter in distinguishing between individuals. The loud calls were correctly classified in $59 \%$, higher classification rate was achieved when the three subtypes of loud calls were analyzed separately ( $71 \%$ type I, $67 \%$ type II, and $94 \%$ type III). Including more parameters to describe the statistical distribution of the frequency amplitudes in the spectrum led to $85 \%$ of correct classification for loud call type II, which was the most common long-distance call recorded during our study. We did not notice any differences between sexes or between localities, but unfortunately due to lack of data from the radio-collared individuals (with known sex) and uneven distribution of the data between two localities these could not be statistically tested. We are aware that the relatively high correct classification rates may be due to limited data set. However, we still believe that our findings confirm the individual variability in long-distance calls in the Philippine tarsier, which provides reliable information about identity of a caller.

Bioacoustic methods can play a great role in the monitoring of species, especially cryptic species, and in this way can also contribute to their conservation. The cryptic nature of the Philippine tarsier, lack of reflective layer tapetum lucidum in the eye, and difficult terrain makes detection of these animals and estimation of their population densities very difficult. The Philippine tarsier is classified as near threatened according to the IUCN Red List [50]. However, its population is still decreasing with the habitat loss and hunting being the main threats. It is only a matter of time until the species will occur on the list of endangered species. Despite the Philippine tarsiers being relatively quiet and not heard every night, an understanding of their vocal activity and repertoire can facilitate population surveys or surveys of distribution range since this cryptic 
species is often heard before they are seen, and thus help to its conservation. Identifying and discriminating among individuals in a population is a noninvasive method that can have important application in species conservation [51, 52]. Nevertheless, it should be taken into consideration that it takes some time to collect a call sample large enough to run a reliable discriminant analysis from free-ranging Philippine tarsiers. The time constrains can be, therefore, limiting for practical applications of this method.

Study of the primate distinctive long-distance calls is important for taxonomy. Loud calls have been used for the reconstruction of phylogeny or as a noninvasive diagnostic tool for discriminating cryptic primate species, including tarsiers $[6,8,9,17,19,20,53-59]$. Taxonomic diversification is very closely related to conservation of different population/species, for example, Tarsius tumpara [60] was placed on critically endangered animals list [61] shortly after its scientific description. Only one species, T. syrichta, lives in the Philippines. Three subspecies of Tarsius syrichta have been described [62] on islands that belonged to former large Pleistocene island of Greater Mindanao ([63] cited in [64]). Tarsius s. syrichta lives on Samar and Leyte, T. s. carbonarius on Mindanao, and T. s. fraterculus on Bohol. Other populations with unresolved status were found on Dinagat, Siargo, and Basilan. These populations may be distinct and regarded as different subspecies [62]. Thus, bioacoustic studies which help to determine the taxonomy of these species can, subsequently, also affect conservation status of different populations.

\section{Acknowledgments}

Special thanks to all coworkers helping with the Tarsius Project, especially Václav Řehák, Cristy Burlace, Felix Sobiono, Radka a Ondřej Huskákovi, Tomáš Daněk, Barbora Hančíková, Dana Ježová, Matyáš Adam, Jana Kaňková, Monika Papoušková, Jose Travero, Sherry Ramayla, Bonn Aure, and others. The authors thank Carlito Pizzaras, Julius Baslot, and their assistants for help with catching of tarsiers. They are thank full for financial support especially to Decin Zoo and the following funding agencies and sponsors: Primate Conservation, Inc., Mobility Fund of Charles University, "Nadání Josefa, Marie and Zdeňky Hlávkových" Foundation, Hedvábná stezka, Koktejl, Humi, Evropská cestovní pojištovna, Sambar sport, Storm, and others. They thank their local partners in the field: Simply Butterflies Conservation Centre, The Philippine Tarsier Foundation, Inc., and Bohol Island State University for cooperation and support. Participation of R. P. was supported by an Internal Grant Agency of the Czech University of Life Sciences Prague CIGA 51120/1313/3104. They thank Research Institute of Animal Sciences that enabled them to use the acoustic software. Thanks to DENR Philippines for providing the permits necessary for their research. They are very grateful to Holly Farmer for the English revisions and the comments on the earlier version of the manuscript, Marek Špinka for valuable comments, and Martin Dienstbier for English revision.

\section{References}

[1] M. L. Becker, E. H. Buder, and J. P. Ward, "Spectrographic description of vocalizations in captive Otolemur garnettii," International Journal of Primatology, vol. 24, no. 2, pp. 415446, 2003.

[2] M. Gamba and C. Giacoma, "Quantitative acoustic analysis of the vocal repertoire of the crowned lemur," Ethology Ecology \& Evolution, vol. 19, no. 4, pp. 323-343, 2007.

[3] M. Gamba and C. Giacoma, "Key issues in the study of primate acoustic signals, an update," Journal of Anthropological Sciences, vol. 88, pp. 215-220, 2010.

[4] T. Geissmann and T. Mutschler, "Diurnal distribution of loud calls in sympatric wild indris (Indri indri) and ruffed lemurs (Varecia variegata): implications for call functions," Primates, vol. 47, no. 4, pp. 393-396, 2006.

[5] J. M. Macedonia, "Individuality in a contact call of the ringtailed lemur (Lemur catta)," American Journal of Primatology, vol. 11, no. 2, pp. 163-179, 1986.

[6] J. C. Masters, "Loud calls of Galago crassicaudatus and G. garnettii and their relation to habitat structure," Primates, vol. 32, no. 2, pp. 153-167, 1991.

[7] E. Zimmermann, "The vocal repertoire of the adult senegal bush baby (Galago senegalensis)," Behaviour, vol. 94, no. 3-4, pp. 212-322, 1985.

[8] E. Zimmermann, "Differentiation of vocalizations in bushbabies (Galaginae) and the significance for assessing phylogenetic relationships," Journal of Zoological Systematics and Evolutionary Research, vol. 28, no. 3, pp. 217-239, 1990.

[9] E. Zimmermann, E. Vorobieva, D. Wrogemann, and T. Hafen, "Use of vocal fingerprinting for specific discrimination of gray (Microcebus murinus) and rufous mouse lemurs (Microcebus rufus)," International Journal of Primatology, vol. 21, no. 5, pp. 837-852, 2000.

[10] S. K. Bearder, "Physical and social diversity among nocturnal primates: a new view based on long term research," Primates, vol. 40, no. 1, pp. 267-282, 1999.

[11] P. Braune, S. Schmidt, and E. Zimmermann, "Spacing and group coordination in a nocturnal primate, the golden brown mouse lemur (Microcebus ravelobensis): the role of olfactory and acoustic signals," Behavioral Ecology and Sociobiology, vol. 58, no. 6, pp. 587-596, 2005.

[12] S. Rasoloharijaona, B. Randrianambinina, P. Braune, and E. Zimmermann, "Loud calling, spacing, and cohesiveness in a nocturnal primate, the Milne Edwards' sportive lemur (Lepilemur edwardsi)," American Journal of Physical Anthropology, vol. 129, no. 4, pp. 591-600, 2006.

[13] C. Bergey and E. Patel, "A preliminary vocal repertoire of the greater bamboo lemur (Prolemur simus): classification and contexts," Nexus, vol. 1, pp. 69-84, 2008.

[14] J. R. MacKinnon and K. S. MacKinnon, "The behavior of wild spectral tarsiers," International Journal of Primatology, vol. 1, no. 4, pp. 361-379, 1980.

[15] I. Neri-Arboleda, P. Stott, and N. P. Arboleda, "Home ranges, spatial movements and habitat associations of the Philippine tarsier (Tarsius syrichta) in Corella, Bohol," Journal of Zoology, vol. 257, no. 3, pp. 387-402, 2002.

[16] P. Y. Wong, C. E. Collins, and J. H. Kaas, "Overview of sensory systems of Tarsius," International Journal of Primatology, vol. 31, no. 6, pp. 1002-1031, 2010.

[17] S. Merker and C. P. Groves, "Tarsius lariang: a new primate species from Western Central Sulawesi," International Journal of Primatology, vol. 27, no. 2, pp. 465-485, 2006. 
[18] C. Niemitz, Biology of Tarsiers, Gustav Fisher, Stuttgart, Germany, 1984.

[19] C. Niemitz, A. Nietsch, S. Warter, and Y. Rumpler, "Tarsius dianae: a new primate species from central Sulawesi (Indonesia)," Folia Primatologica, vol. 56, no. 2, pp. 105-116, 1991.

[20] A. Nietsch, "Duet vocalizations among different populations of Sulawesi tarsiers," International Journal of Primatology, vol. 20, no. 4, pp. 567-583, 1999.

[21] A. Nietsch, "Outline of the vocal behavior of Tarsius spectrum: call features, associated behaviors, and biological functions," in Tarsiers: Past, Present, and Future, P. C. Wright, E. L. Simons, and S. Gursky, Eds., pp. 196-220, Rutgers University Press, New Brunswick, NJ, USA, 2003.

[22] C. Niemitz, "Outline of the behaviour of Tarsius bancanus," in The Study of Prosimian Behavior, G. A. Doyle and R. D. Martin, Eds., pp. 631-660, Academic Press, New York, NY, USA, 1979.

[23] I. Yustian, Ecology and Conservation Status of Tarsius bancanus saltator on Belitung Island, Indonesia, Cuvillier, Göttingen, Germany, 2007.

[24] R. H. Crompton and P. M. Andau, "Ranging, activity rhythms, and sociality in free-ranging Tarsius bancanus: a preliminary report," International Journal of Primatology, vol. 8, no. 1, pp. 43-71, 1987.

[25] C. H. Wharton, "The tarsier in captivity," Journal of Mammalogy, vol. 31, no. 3, pp. 260-268, 1950.

[26] P. C. Wright and E. L. Simons, "Calls of the Mindanao tarsier," American Journal of Physical Anthropology, vol. 63, p. 236, 1984.

[27] M. Gamba, C. Colombo, and C. Giacoma, "Acoustic cues to caller identity in lemurs: a case study," Journal of Ethology, vol. 30, no. 1, pp. 191-196, 2012.

[28] C. T. Snowdon and J. Cleveland, "Individual recognition of contact calls by pygmy marmosets," Animal Behaviour, vol. 28, no. 3, pp. 717-727, 1980.

[29] D. D. Jorgensen and J. A. French, "Individuality but not stability in marmoset long calls," Ethology, vol. 104, no. 9, pp. 729-742, 1998.

[30] C. A. Chapman and D. M. Weary, "Variability in spider monkeys' vocalizations may provide basis for individual recognition," American Journal of Primatology, vol. 22, no. 4, pp. 279-284, 1990.

[31] R. Steenbeek and P. Assink, "Individual differences in long-distance calls of male wild Thomas langurs (Presbytis thomasi)," Folia Primatologica, vol. 69, no. 2, pp. 77-80, 1998.

[32] S. A. Wich, S. Koski, H. de Vries, and C. P. Van Schaik, "Individual and contextual variation in Thomas langur male loud calls," Ethology, vol. 109, no. 1, pp. 1-13, 2003.

[33] R. A. Delgado, "Sexual selection in the loud calls of male primates: signal content and function," International Journal of Primatology, vol. 27, no. 1, pp. 5-25, 2006.

[34] M. Řeháková-Petrů, L. Peške, and T. Daněk, "Predation on a wild Philippine tarsier (Tarsius syrichta)," Acta Ethologica. In press.

[35] D. S. Jachowski and C. Pizzaras, "Introducing an innovative semi-captive environment for the Philippine tarsier (Tarsius syrichta)," Zoo Biology, vol. 24, no. 1, pp. 101-109, 2005.

[36] M. Dagosto, D. L. Gebo, and C. Dolino, "Positional behavior and social organization of the Philippine tarsier (Tarsius syrichta)," Primates, vol. 42, no. 3, pp. 233-243, 2001.

[37] J. Fischer, K. Hammerschmidt, D. L. Cheney, and R. M. Seyfarth, "Acoustic features of female chacma baboon barks," Ethology, vol. 107, no. 1, pp. 33-54, 2001.
[38] L. Schrader and K. Hammerschmidt, "Computer-aided analysis of acoustic parameters in animal vocalisations: a multiparametric approach," Bioacoustics, vol. 7, no. 4, pp. 247-265, 1997.

[39] P. M. Waser and C. H. Brown, "Is there a "sound window" for primate communication?" Behavioral Ecology and Sociobiology, vol. 15, no. 1, pp. 73-76, 1984.

[40] S. L. Gursky, "Infant care in the spectral tarsier (Tarsius spectrum) Sulawesi, Indonesia," International Journal of Primatology, vol. 15, no. 6, pp. 843-853, 1994.

[41] M. A. Ramsier, A. J. Cunningham, G. L. Moritz et al., "Primate communication in the pure ultrasound," Biology Letters. In press.

[42] R. Policht, A. Karadžos, and D. Frynta, "Comparative analysis of long-range calls in equid stallions (Equidae): are acoustic parameters related to social organization?" African Zoology, vol. 46, no. 1, pp. 18-26, 2011.

[43] D. T. Blumstein and K. B. Armitage, "Does sociality drive the evolution of communicative complexity? A comparative test with ground-dwelling sciurid alarm calls," American Naturalist, vol. 150, no. 2, pp. 179-200, 1997.

[44] A. Le Roux, M. I. Cherry, and M. B. Manser, "The vocal repertoire in a solitary foraging carnivore, Cynictis penicillata, may reflect facultative sociality," Naturwissenschaften, vol. 96, no. 5, pp. 575-584, 2009.

[45] K. McComb and S. Semple, "Coevolution of vocal communication and sociality in primates," Biology Letters, vol. 1, no. 4, pp. 381-385, 2005.

[46] R. H. Crompton and P. M. Andau, "Locomotion and habitat utilization in free-ranging Tarsius bancanus: a preliminary report," Primates, vol. 27, no. 3, pp. 337-355, 1986.

[47] S. Gursky, "Group size and composition in the spectral tarsier, Tarsius spectrum: implication for social structure," Tropical Biodiversity, vol. 3, pp. 57-62, 1995.

[48] S. Gursky, "Determinants of gregariousness in the spectral tarsier (prosimian: Tarsius spectrum)," Journal of Zoology, vol. 256, no. 3, pp. 401-410, 2002.

[49] S. Gursky, "Associations between adult spectral tarsiers," American Journal of Physical Anthropology, vol. 128, no. 1, pp. 74-83, 2005.

[50] M. Shekelle and I. Arboleda, Tarsius syrichta. In: IUCN 2011. IUCN Red list of threatened species. Version 2011, 2008.

[51] P. K. McGregor, T. M. Peake, M. Gilbert et al., "Communication behaviour and conservation," in Behaviour and Conservation, L. M. Gosling and W. J. Sutherland, Eds., pp. 261-282, Cambridge University Press, Cambridge, UK, 2000.

[52] A. M. R. Terry, T. M. Peake, and P. K. McGregor, "The role of vocal individuality in conservation," Frontiers in Zoology, vol. 2, no. 1, 2005.

[53] P. Braune, S. Schmidt, and E. Zimmermann, "Acoustic divergence in the communication of cryptic species of nocturnal primates (Microcebus ssp.)," BMC Biology, vol. 6, article 19, 2008.

[54] J. A. Burton and A. Nietsch, "Geographical variation induet songs of Sulawesi tarsiers: evidence for new cryptic species in South and Southeast Sulawesi," International Journal of Primatology, vol. 31, no. 6, pp. 1123-1146, 2010.

[55] J. C. Mitani and J. Gros-Louis, "Species and sex differences in the screams of chimpanzees and bonobos," International Journal of Primatology, vol. 16, no. 3, pp. 393-411, 1995.

[56] M. Méndez-Cárdenas, B. Randrianambinina, A. Rabesandratana, S. Rasoloharijaona, and E. Zimmermann, "Geographic variation in loud calls of sportive lemurs (Lepilemur ssp.) 
and their implications for conservation," American Journal of Primatology, vol. 70, no. 9, pp. 828-838, 2008.

[57] A. Nietsch and M. L. Kopp, "Role of vocalization in species differentiation of Sulawesi tarsiers," Folia Primatologica, vol. 69, supplement 1, pp. 371-378, 1998.

[58] J. F. Oates and T. F. Trocco, "Taxonomy and phylogeny of black-and-white colobus monkeys. Inferences from an analysis of loud call variation," Folia Primatologica, vol. 40, no. $1-2$, pp. 83-113, 1983.

[59] C. T. Snowdon, A. Hodun, A. L. Rosenberger, and A. F. Coimbra-Filho, "Long-call structure and its relation to taxonomy in lion tamarins," American Journal of Primatology, vol. 11, no. 3, pp. 253-261, 1986.

[60] M. Shekelle, C. Groves, S. Merker, and J. Supriatna, "Tarsius tumpara: a new tarsier species from Siau Island, North Sulawesi," Primate Conservation, vol. 23, pp. 55-64, 2008.

[61] M. Shekelle and A. Salim, Tarsius tumpara. In: IUCN 2011. IUCN Red list of threatened species. Version 2011.2, 2011.

[62] D. Brandon-Jones, A. A. Eudey, T. Geissmann et al., "Asian primate classification," International Journal of Primatology, vol. 25, no. 1, pp. 97-164, 2004.

[63] L. R. Heaney, "Zoogeographic evidence for middle and late Pleistocene land bridges to the Philippine Islands," Modern Quaternary Research in Southeast Asia, vol. 9, pp. 127-144, 1985.

[64] M. Dagosto, D. L. Gebo, and C. N. Dolino, "The natural history of the Philippine tarsier (Tarsius syrichta)," in Tarsiers: Past, Present, and Future, P. C. Wright, E. L. Simons, and S. Gursky, Eds., pp. 237-259, Rutgers University Press, New Brunswick, NJ, USA, 2003. 

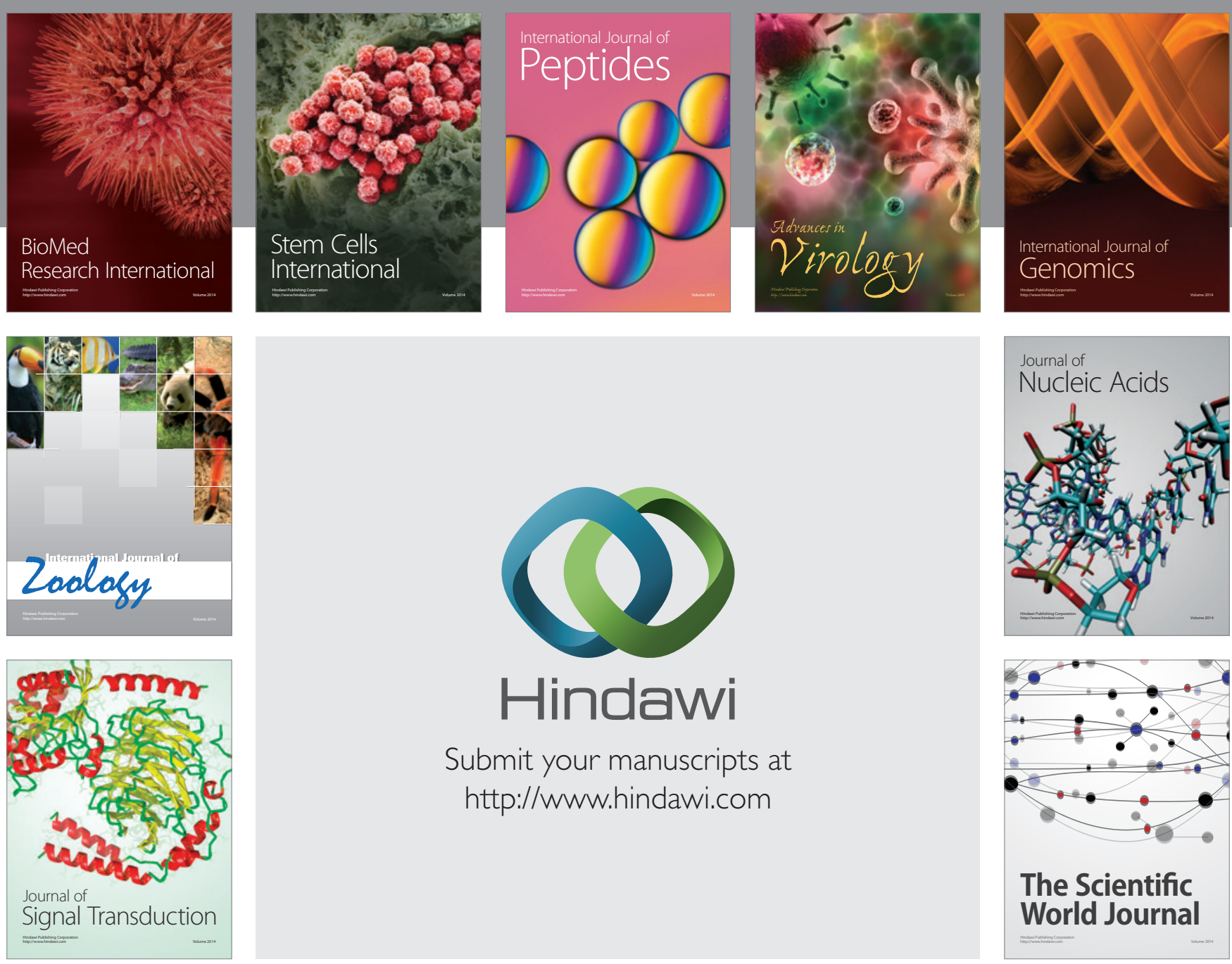

Submit your manuscripts at

http://www.hindawi.com
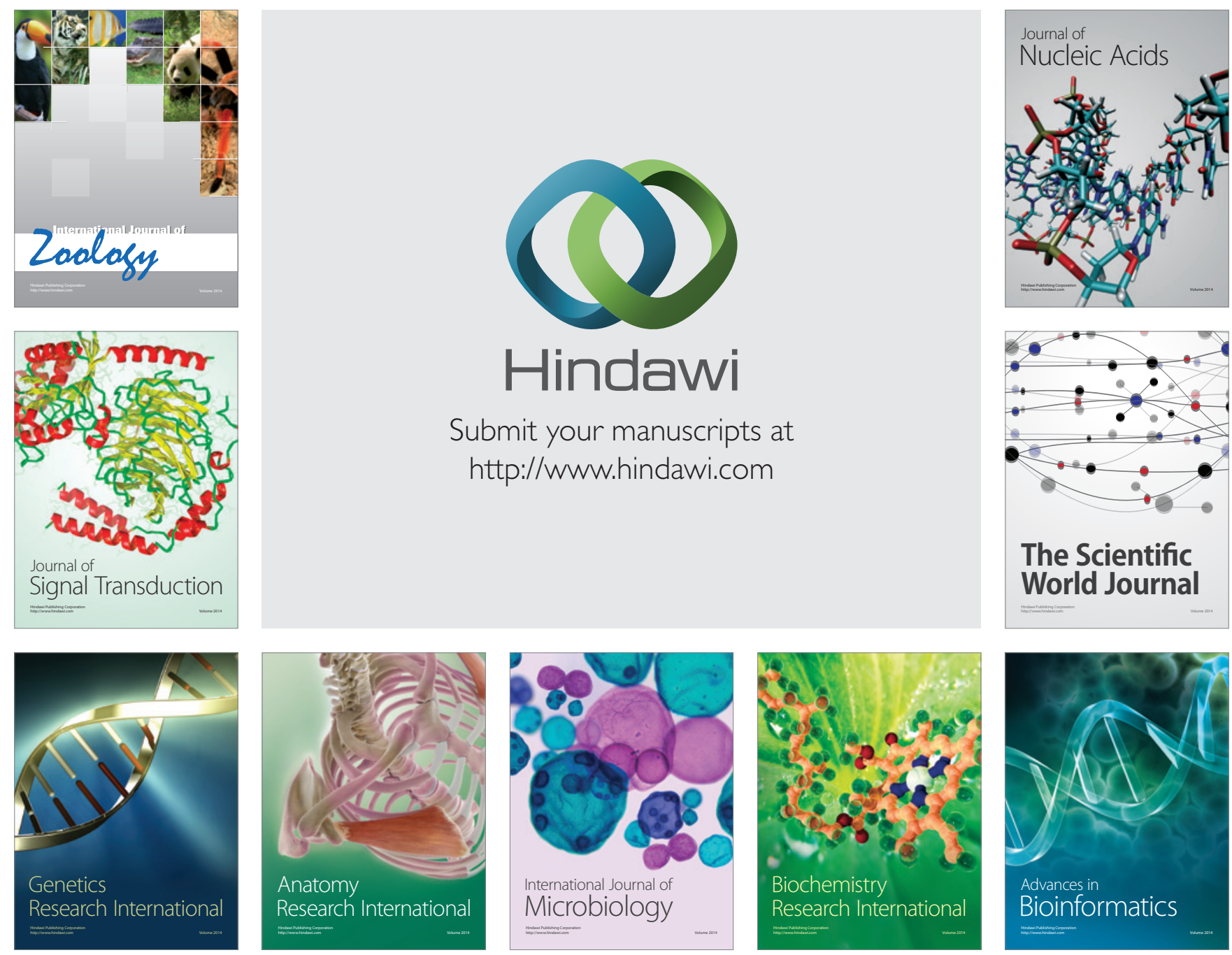

The Scientific World Journal
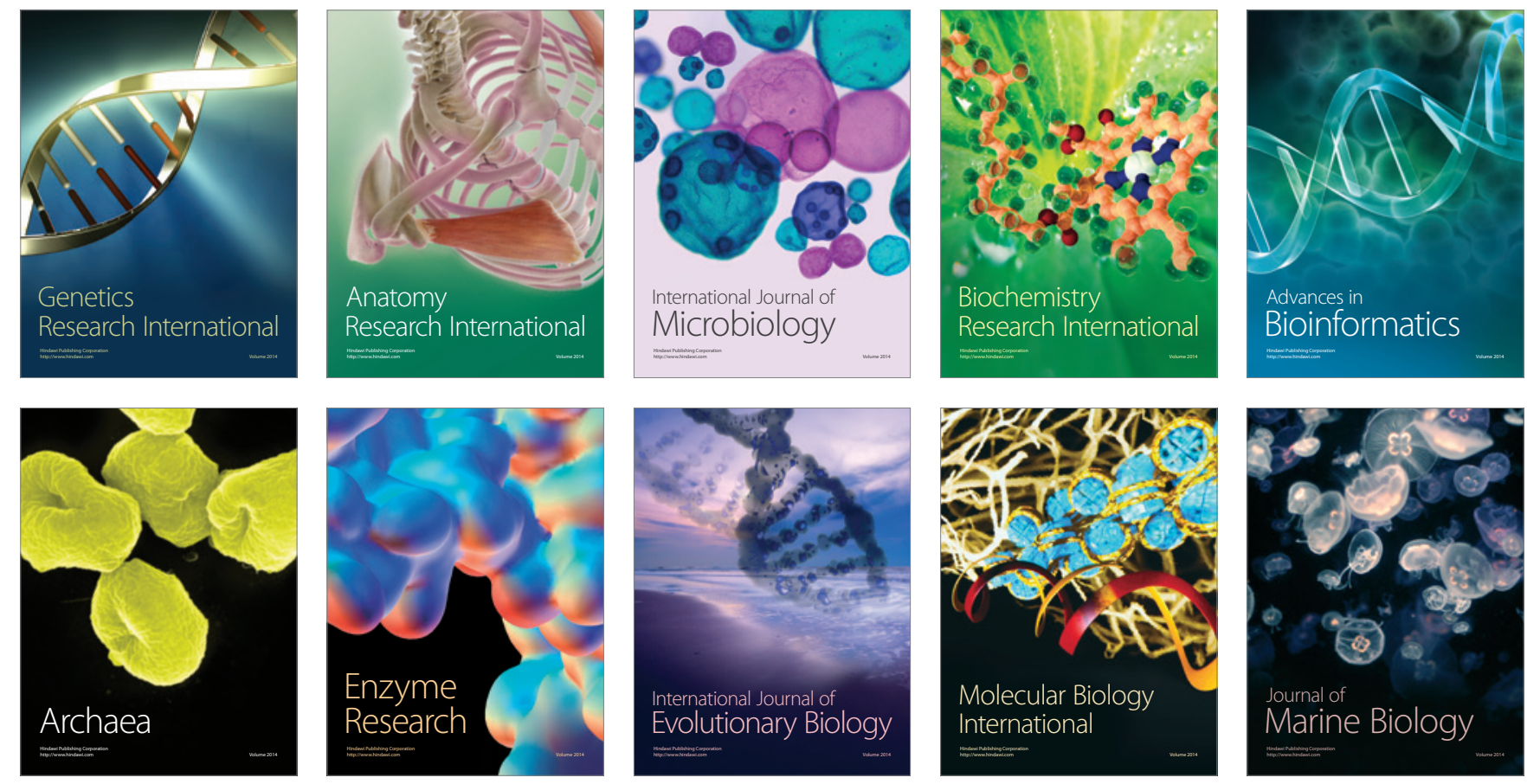